\title{
The disparity between long-term survival in patients with and without diabetes following a first myocardial infarction did not change between 1989 and 2006: an analysis of 6,776 patients in the Northern Sweden MONICA Study
}

\author{
M. Eliasson • J.-H. Jansson • D. Lundblad • U. Näslund
}

Received: 8 March 2011 / Accepted: 13 June 2011 / Published online: 21 July 2011

(C) Springer-Verlag 2011

\begin{abstract}
Aims/hypothesis Long-term survival after myocardial infarction (MI) has improved in the population, but data on diabetic patients is lacking. We analysed survival for up to 18 years after a first MI in patients with or without diabetes. Methods The Northern Sweden MONICA Myocardial Infarction Registry was linked to the Cause-of-Death Registry for a total of 6,776 patients, 25-64 years of age, with a first MI during 1989-2006. Prehospital deaths were included. Follow-up ended on 30 August 2008.

Results Sixteen per cent had diabetes. Median follow-up time was 6.8 years, and the study included 50,667 patientyears. One third of the non-diabetic patients died vs half of the diabetic patients. Median survival for non-diabetic men was 227 months and for diabetic men 123 months. Corresponding figures for the non-diabetic and diabetic women were 222 and 81 months respectively. Men with diabetes had an age-adjusted HR for all-cause mortality of $1.56(95 \%$ CI $1.39,1.79)$ vs men without diabetes.
\end{abstract}

M. Eliasson · J.-H. Jansson • D. Lundblad • U. Näslund

Department of Public Health and Clinical Medicine,

Umeå University,

Umeå, Sweden

M. Eliasson $(\bowtie) \cdot D$. Lundblad

Department of Medicine, Sunderby Hospital,

97130 Luleå, Sweden

e-mail: mats.eliasson@nll.se

J.-H. Jansson

Department of Medicine and Geriatrics, Skellefteå Hospital,

Skellefteå, Sweden

U. Näslund

Department of Cardiology, Heart Centre, University Hospital,

Umeå, Sweden
Mortality risk was higher among diabetic women, HR $1.97(1.62,2.39)$ (diabetes $\times$ sex interaction, $p=0.03$ ). Survival increased for three consecutive cohorts and was higher in non-diabetic patients for all durations of follow-up and in all three cohorts. The interaction of diabetes $\mathrm{x}$ cohort was not significant over time $(p=0.5)$ and HRs did not differ either.

Conclusions/interpretation Long-term survival after a first MI is markedly lower in diabetic patients, especially among women, over an 18-year observation time. Although survival has improved in diabetic patients, the effect of diabetes upon mortality has not diminished.

Keywords Diabetes mellitus $\cdot$ Mortality $\cdot$ Myocardial infarction $\cdot$ Sex $\cdot$ Time trends

\section{Abbreviations}

MI Myocardial infarction

MONICA MONItoring of trends and determinants in CArdiovascular disease

\section{Introduction}

The risk of fatal cardiovascular diseases is elevated for diabetic patients, and even more for women than men with diabetes [1]. A secular decline in short-term mortality from ischaemic heart disease among diabetic patients, in parallel with non-diabetic patients, has been confirmed in population-based studies, both in the USA $[2,3]$ and in Europe [4].

Long-term mortality after myocardial infarction (MI) in diabetic patients is $30-50 \%$ higher than among non-diabetic patients [5, 6], and even further increased in diabetic 
women [7-9]. Time trends in 1-year survival reported from national surveys in Sweden and Finland have shown no decrease in the mortality gap [6,9].

We wished to assess the impact of intensified primary and secondary prevention, including coronary revascularisation, on mortality among diabetic patients after a first MI. Towards this goal, survival data over periods much longer than 1 year are needed to describe the secular trends over a period that includes the introduction of evidencebased cardiovascular diabetology [10]. In addition, data should include prehospital deaths [11].

We analysed survival up to 18 years after a first ever MI suffered between 1989 and 2006 in diabetic and nondiabetic patients in a well-defined population taking sex and time trends into consideration. The main research question was if the difference in long-term mortality rate between patients with or without diabetes has diminished over time. A secondary aim was to study the interaction between sex and diabetes on the long-term mortality rate.

\section{Methods}

The Northern Sweden MONICA Myocardial Infarction Registry is population-based and includes all MIs in the two northernmost counties in Sweden according to the WHO MONICA criteria $[12,13]$. All deaths out of hospital are evaluated for possible MIs.

Between 1 January 1989 and 31 December 2006, a total of 6,890 patients, 25-64 years of age, fulfilled the MONICA criteria and were diagnosed as a definite first MI. Times for onset of MI or records regarding the presence of diabetes were missing in 114 patients. Complete data were available for 6,776 patients. The diagnosis of diabetes was based on medical records or diabetes diagnosed during the event. Data were missing regarding treatment of diabetes (3\%), angina (15\%), hypertension $(4 \%)$ and smoking (16\%). No data were available for lipid-lowering treatments. The population at-risk was 258,576 on 31 December 2009.

All patients were followed-up for information on vital status using The Swedish Cause of Death Registry until 30 August 2008. Patients not identified in the register were assumed to be alive at that date and censored. The endpoint studied was death from any cause. The Northern Sweden MONICA Study was approved by the Research Ethics Committee of Umeå University. Patients or relatives of non-survivors gave written consent.

Statistical analyses The patients were separated into three cohorts representing the year of onset of MI: 1989-1994, 1995-2000 and 2001-2006. Survival time was calculated as the number of months between the date of the MI and the date of death, or 30 August 2008, and analysed with Kaplan-Meier product limit estimate. The hypothesis test of no difference in survival between patients with and without diabetes was performed using Cox regression analysis. The proportional hazard assumption was assessed using time-dependent covariates, i.e. including the interaction covariate $\times T$ in the model. As there was evidence of non-proportional hazard with age, further analyses were stratified by age group $(25-50,51-56,57-60$ and $61-$ 64 years). Test for diabetes $\times$ sex and diabetes $\times$ cohort interactions were performed. Absolute differences in survival at specific time points (1, 5 and 10 years) were calculated and relative risk differences were calculated as the absolute risk difference divided by the risk in the nondiabetic group. IBM SPSS Statistics 18.3 was used for statistical analysis.

\section{Results}

Between 1989 and 2006, 5,266 men and 1,510 women in the age group 25 through 64 years had a first ever MI (Table 1). The prevalence of diabetes increased from $12 \%$ to $18 \%$ in men and from $16 \%$ to $21 \%$ in women. Diabetic patients more often had angina pectoris but were less often smokers. Men with diabetes were more often treated for hypertension than men without diabetes, whereas the opposite was true for women.

At onset of the first MI, $29 \%$ of the diabetic patients were treated with diet only, $30 \%$ with oral glucose-lowering agents, $36 \%$ with insulin only and 5\% with oral glucoselowering agents and insulin. Women were more often treated with insulin than men ( $46 \%$ vs $32 \%$ ), and less often with oral glucose-lowering agents (23\% vs 33\%). Treatment with diet only or insulin only decreased over time, whereas combination therapy increased and the use of oral glucose-lowering agents was stable. These changes were similar in both men and women.

Median follow-up time was 6.8 years and total follow-up was 50,667 patient-years, during which a total of $34.7 \%$ of the non-diabetic patients and $50.6 \%$ of the diabetic patients died. Among non-diabetic men $14.3 \%$ died before admission to hospital, and among diabetic men $16.5 \%$ died. The corresponding numbers for women were $11.1 \%$ and $10.2 \%$ respectively.

Median survival for non-diabetic patients was 227 months and for diabetic patients 115 months. In a Cox regression analysis, diabetic patients had an age-adjusted HR for allcause mortality of 1.65 (95\% CI $1.50,1.82)$ compared with non-diabetic patients (Table 2).

After exclusion of patients who died before reaching hospital, mean survival in non-diabetic patients was 
Table 1 Baseline data on 6,776 patients 25-64 years of age with a first MI during 1989-2006

\begin{tabular}{|c|c|c|c|c|c|c|c|c|c|c|}
\hline \multirow[t]{2}{*}{ Period } & \multicolumn{2}{|l|}{$n$} & \multicolumn{2}{|l|}{ Age (years) } & \multicolumn{2}{|l|}{ Angina $(\%)$} & \multicolumn{2}{|c|}{ Hypertension (\%) } & \multicolumn{2}{|c|}{ Regular smoking (\%) } \\
\hline & $\begin{array}{l}\text { Non-diabetic } \\
\text { patients }\end{array}$ & $\begin{array}{l}\text { Diabetic } \\
\text { patients }\end{array}$ & $\begin{array}{l}\text { Non-diabetic } \\
\text { patients }\end{array}$ & $\begin{array}{l}\text { Diabetic } \\
\text { patients }\end{array}$ & $\begin{array}{l}\text { Non-diabetic } \\
\text { patients }\end{array}$ & $\begin{array}{l}\text { Diabetic } \\
\text { patients }\end{array}$ & $\begin{array}{l}\text { Non-diabetic } \\
\text { patients }\end{array}$ & $\begin{array}{l}\text { Diabetic } \\
\text { patients }\end{array}$ & $\begin{array}{l}\text { Non-diabetic } \\
\text { patients }\end{array}$ & $\begin{array}{l}\text { Diabetic } \\
\text { patients }\end{array}$ \\
\hline \multicolumn{11}{|l|}{ Men } \\
\hline 1989-1994 & 1,678 & 235 & 55.1 & 56.8 & 28.9 & 38.2 & 40.2 & 59.7 & 39.8 & 27.3 \\
\hline 1995-2000 & 1,446 & 261 & 55.2 & 55.8 & 29.9 & 39.4 & 30.5 & 50.4 & 43.9 & 36.6 \\
\hline 2001-2006 & 1,353 & 293 & 55.5 & 56.6 & 22.8 & 36.6 & 32.4 & 57.5 & 38.9 & 34.5 \\
\hline 1989-2006 & 4,477 & 789 & 55.3 & 56.4 & 27.1 & 38.0 & 34.7 & 56.0 & 40.7 & 32.5 \\
\hline \multicolumn{11}{|l|}{ Women } \\
\hline 1989-1994 & 422 & 82 & 56.1 & 59.2 & 27.1 & 28.6 & 47.9 & 34.2 & 52.4 & 32.4 \\
\hline 1995-2000 & 420 & 74 & 55.7 & 57.5 & 26.7 & 42.3 & 39.0 & 36.9 & 60.5 & 38.8 \\
\hline 2001-2006 & 403 & 109 & 56.0 & 56.8 & 21.8 & 38.3 & 41.7 & 32.0 & 55.9 & 55.3 \\
\hline 1989-2006 & 1,245 & 265 & 55.9 & 57.7 & 25.0 & 37.4 & 42.9 & 34.0 & 56.0 & 43.3 \\
\hline
\end{tabular}

184 months $(95 \%$ CI 182, 187) and in diabetic patients 137 months (95\% CI 130, 144; medians could not be calculated). Age-adjusted HR was 2.10 (95\% CI 1.87, 2.36).

An interaction between diabetes and sex was found $(p=$ $0.03)$. Median survival time for non-diabetic men was 227 months and for diabetic men 123 months. The corresponding times for women were 222 and 81 months respectively. The higher mortality rate among diabetic patients was more pronounced among women then among men, although the age-adjusted HRs had overlapping confidence intervals (Table 2).

For each of the three successive cohorts, mortality rates decreased, both for diabetic and non-diabetic patients (Fig. 1). Within each cohort the mortality rate was higher among diabetic patients. The test for interaction between the effect of diabetes and cohort was not significant ( $p=$ $0.5)$. The HRs were identical for the first and last period and insignificantly higher during the second period (data not shown).

Adjusting for age, sex and cohort did not affect the HR (Table 2). Neither did further adjusting for the presence of angina pectoris, hypertension or smoking influence the HR significantly. However, the HRs in diabetic men decreased and in diabetic women increased, leading to a larger difference between the estimates for the two sexes.
For any duration of follow-up and through all three time periods, a higher proportion of non-diabetic patients were alive (Table 3). Five-year survivals after a first MI among the non-diabetic men and women were $76 \%$ and $76 \%$, respectively, whereas among the diabetic patients the figures were $62 \%$ and $57 \%$ respectively.

For the non-diabetic men and women who reached the hospital alive, $87.3 \%$ and $85.0 \%$, respectively, were alive after 5 years. Corresponding figures for diabetic patients were $74.4 \%$ and $63.0 \%$ respectively.

The absolute difference in 5-year survival increased from the first to the second cohort but declined in the third cohort, most prominently in women. Five years after a first MI suffered during the third period, 2001-2006, the proportions alive were 11 percentage points and 15 percentage points lower in diabetic men and women than in the non-diabetic patients, the lowest difference in any of the three cohorts. Although no linear decrease in relative difference of survival was noted, it is evident that during the latest period both 1- and 5-year relative survival differences were lower than in the previous two periods.

With longer follow-up times, there was an increasing difference in the survival between non-diabetic patients and diabetic patients. For the whole study period, 10-year survival after an MI was 15 percentage points and 23 percentage points lower in diabetic men and women, respectively.

Table 2 HR for all-cause mortality in diabetic patients compared with non-diabetic patients

\begin{tabular}{llccccc}
\hline Variable & HR (crude) & Stratified by age group & Add sex & Add cohort & Add angina & Add HT and smoking \\
\hline Total & $1.73(1.57,1.91)$ & $1.65(1.50,1.82)$ & $1.65(1.50,1.82)$ & $1.70(1.54,1.87)$ & $1.62(1.46,1.81)$ & $1.59(1.38,1.83)$ \\
Men & $1.63(1.46,1.83)$ & $1.56(1.39,1.74)$ & & $1.59(1.43,1.79)$ & $1.51(1.33,1.71)$ & $1.43(1.22,1.69)$ \\
Women & $2.07(1.70,2.50)$ & $1.97(1.62,2.39)$ & & $2.02(1.67,2.45)$ & $2.04(1.64,2.54)$ & $2.18(1.64,2.89)$ \\
\hline
\end{tabular}

Crude analysis, stratified by age group and with successive addition of sex, time period (cohort), previous angina, hypertension (HT) and smoking (95\% CI) 
Fig. 1 Survival after a first MI in diabetic and non-diabetic patients according to sex and year of onset. Logrank test $p<0.001$ for all comparisons. Non-diabetic patients denoted by bold lines and diabetic patients with thin line. a-c Men, cohort 1989-1994 (a), cohort 1995-2000 (b), cohort 2001-2006 (c). d-f Women, cohort 1989-1994 (d), cohort 1995-2000 (e), cohort 2001-2006 (f)
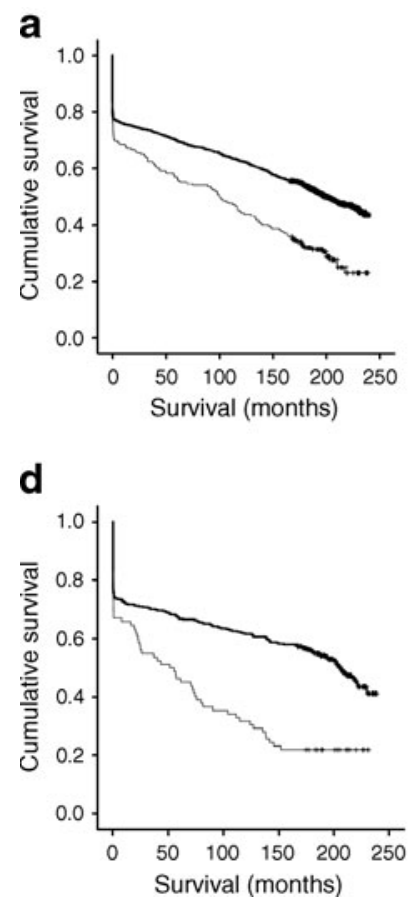

\section{Discussion}

Long-term survival after a first MI in middle-age is markedly lower in diabetic patients than in non-diabetic patients. Although survival has improved continuously, the difference between diabetic and non-diabetic patients remains substantial in both absolute and relative terms and showed little evidence of decreasing during the 18-year observation period. Furthermore, the increased mortality risk among diabetic patients is even higher in women than in men. When including deaths before admission to hospital, the increased risk for diabetic patients is attenuated as
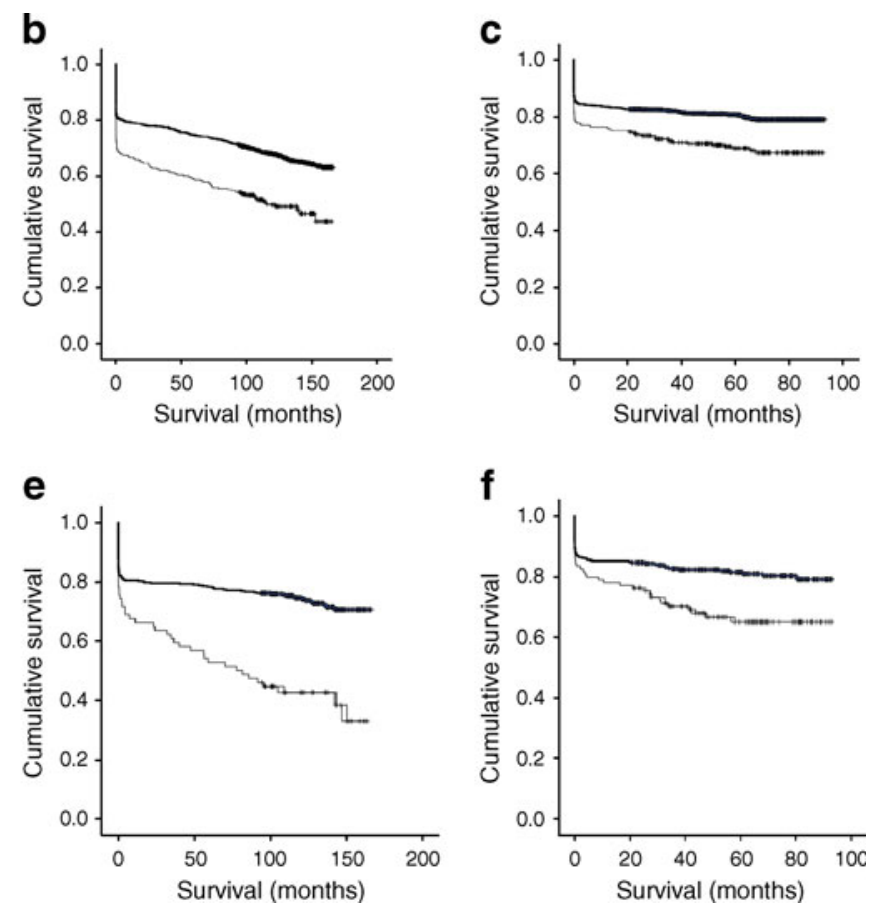

compared with studying only those admitted alive, which most often has been reported previously.

The MONICA Myocardial Infarction Registry has operated consistently according to the WHO manual since 1986, using strict and uniform criteria for case capture and ascertainment, thus ensuring high internal validity. The background population has been very stable, and the prevalence of diabetes in this age group in the population of northern Sweden has been unchanged [14]. An important advantage is the inclusion of all MIs, including prehospital deaths. This reduces the risk of bias due to differential mortality according to sex and diabetes before reaching

Table 3 Survival according to event year, sex and presence of diabetes (\%)

\begin{tabular}{|c|c|c|c|c|c|c|c|}
\hline \multirow{2}{*}{$\begin{array}{l}\text { Years from } \\
\text { event }\end{array}$} & \multirow[t]{2}{*}{ Event year } & \multicolumn{3}{|l|}{ Men } & \multicolumn{3}{|l|}{ Women } \\
\hline & & $\begin{array}{l}\text { No diabetes } \\
\text { Proportion } \\
\text { surviving at } \\
\text { end of interval }(\%)\end{array}$ & $\begin{array}{l}\text { Diabetes } \\
\text { Proportion } \\
\text { surviving at end } \\
\text { of interval }(\%)\end{array}$ & $\begin{array}{l}\text { Absolute/relative } \\
\text { difference in survival } \\
(\% \text {-points } / \%)\end{array}$ & $\begin{array}{l}\text { No diabetes } \\
\text { Proportion } \\
\text { surviving at end } \\
\text { of interval }(\%)\end{array}$ & $\begin{array}{l}\text { Diabetes } \\
\text { Proportion } \\
\text { surviving at end } \\
\text { of interval (\%) }\end{array}$ & $\begin{array}{l}\text { Absolute/relative } \\
\text { difference in survival } \\
(\% \text {-points } / \%)\end{array}$ \\
\hline \multirow[t]{4}{*}{1} & 1989-1994 & 75.6 & 68.1 & $7.5 / 9.9$ & 72.0 & 65.9 & $6.1 / 8.5$ \\
\hline & $1995-2000$ & 79.2 & 66.7 & $12.5 / 15.8$ & 80.5 & 66.2 & $14.3 / 17.4$ \\
\hline & 2001-2006 & 83.6 & 76.5 & $7.1 / 8.5$ & 85.1 & 78.0 & $7.1 / 8.3$ \\
\hline & 1989-2006 & 79.2 & 70.7 & $8.5 / 10.7$ & 79.1 & 70.9 & $8.2 / 10.3$ \\
\hline \multirow[t]{4}{*}{5} & 1989-1994 & 69.7 & 56.2 & $13.5 / 19.4$ & 66.8 & 46.3 & $20.5 / 30.7$ \\
\hline & 1995-2000 & 74.7 & 58.6 & $16.1 / 21.5$ & 78.3 & 52.7 & $25.6 / 32.6$ \\
\hline & 2001-2006 & 81.2 & 70.0 & $11.2 / 13.8$ & 81.9 & 67.0 & $14.9 / 18.2$ \\
\hline & 1989-2006 & 75.6 & 62.1 & $13.5 / 17.6$ & 75.6 & 56.6 & $19.0 / 25.1$ \\
\hline \multirow[t]{3}{*}{10} & 1989-1994 & 62.6 & 44.3 & $18.3 / 29.2$ & 61.6 & 31.7 & $29.9 / 48.5$ \\
\hline & 1995-2000 & 68.4 & 51.0 & $17.4 / 25.4$ & 74.8 & 43.2 & $31.6 / 42.2$ \\
\hline & 1989-2006 & 69.9 & 55.0 & $14.9 / 21.3$ & 72.4 & 49.4 & $23.0 / 31.8$ \\
\hline
\end{tabular}

Differences in survival given as absolute and relative risk difference (percentage points and per cent) 
hospital [11, 15]. A long study period and a large number of patients allowed us to observe over 50,000 patientyears, adding further strength. The Swedish personal identification number reliably accounts for all deaths [16]. The main limitation, and a weakness in the original MONICA project, is the narrow age span as we only included patients below the age of 65 years. We caution against extrapolating these data to the large group of older diabetic patients.

Previous studies are limited in different ways. Some are based only on patients treated at hospital $[5,7,8]$, thereby neglecting the large number of prehospital deaths, which influence estimated mortality risk [11]. Some only included patients admitted to coronary care units [6]. In one case, only diabetic patients being treated with oral drugs or insulin were included [9]. Others cover a short time span [8], follow only one cohort over time and do not inform regarding secular trends [5]. Only a few report on mortality beyond 1 year $[5,6,8]$ or exclusively after a first ever MI $[5,8,9]$. Three studies have however included a nationwide coverage and all ages $[5,6,9]$.

There is agreement on the increased short-term mortality risk for diabetic patients suffering an $\mathrm{MI}$ and the amplitude of the risk increase, between $40 \%$ and $100 \%$, is similar across studies, countries and time periods. Our long-term follow-up is unique and points to an increasing difference in survival with longer follow-up. But in patients with an MI after 2000 we found less risk difference after 1 and 5 years, although statistical testing could not confirm any significant changes between cohorts.

Analyses of secular trends are instrumental to determine if the evidence-based efforts on improving care of patients with diabetes and MI have succeeded. The longest time series published comes from Finnish national data between 1988 and 2002 and reports similar decreases in fatality rates between diabetic and non-diabetic patients with no trends towards a reduced difference [9], which our data corroborate over a longer time period. Data from Sweden and Holland $[6,8]$ 1995-2003 are also in accordance with the longer secular trends.

A failure to reduce the increased mortality risk among diabetic patients could be due to insufficient control of risk factors, both before and after a coronary event. Data from the Framingham Study point to a greater decrease in cholesterol, similar decline in blood pressure and greater increase in body weight in diabetic patients compared with non-diabetic patients between 1970 and 2005 [17]. Between 1996 and 2003, Swedish type 2 diabetic patients showed decreased $\mathrm{HbA}_{1 \mathrm{c}}$, blood pressure and cholesterol, although few patients achieved target levels [18]. Whether these improvements are in parallel with, or stronger than, those in the non-diabetic population in Sweden is not known.
Patients with diabetes have increased mortality after revascularisation. High-quality evidence supports the use of drug-eluting stents rather than bare metal stents, and coronary artery bypass instead of percutaneous intervention in the case of multivessel disease, as recently reviewed [10]. Information on the implementation of these procedures in Sweden is crucial to the interpretation of our findings.

Most, but not all [5, 9], studies note higher risk among diabetic women. The reason for this is still unclear, but diabetic women were more often smokers than diabetic men in our study. Adjusting for baseline differences did not remove the disparity. On the contrary, an even higher risk was noted among women. We had no information on lipidlowering treatment, which could serve as a confounder. Unequal access to coronary interventions is also possible.

Patients with diabetes have seemingly benefited from the implementation of evidence-based cardiovascular prevention and intervention, but these measures have not reduced their excess mortality risk. This challenges both clinical medicine and research. To decrease targets for blood pressure and $\mathrm{HbA}_{1 \mathrm{c}}$ even further seems not to be the solution. Would intensified preventive measures regarding cholesterol levels and smoking be possible to achieve in a cost-effective way, and would diabetic people accept even tougher regimens? Or are we barking up the wrong tree? Are we missing alternative pathways? Further analyses of long-term outcome when best available care has persistently been delivered over prolonged periods may elucidate the answers to these questions.

Acknowledgements This work was supported by grants from Norrbotten and Västerbotten County Councils, the Swedish Research Council (VR) and the Joint Committee of Northern Sweden Health Care Region. Marie Eriksson at the Statistical Department of Umeå University gave advice on the statistical analysis.

Contribution statement M.E. designed the study, analysed data and drafted the article. J.H.J., D.L. and U.N. contributed the analysis and interpretation of data and revised the article for important intellectual content. All the authors approved the final version.

Duality of interest The authors declare that there is no duality of interest associated with this manuscript.

\section{References}

1. Huxley R, Barzi F, Woodward M (2006) Excess risk of fatal coronary heart disease associated with diabetes in men and women: meta-analysis of 37 prospective cohort studies. BMJ 332:73-78

2. Gregg EW, Gu Q, Cheng YJ, Narayan KM, Cowie CC (2007) Mortality trends in men and women with diabetes, 1971 to 2000. Ann Intern Med 147:149-155

3. Gu K, Cowie CC, Harris MI (1999) Diabetes and decline in heart disease mortality in US Adults. JAMA 281:1291-1297 
4. Dale AC, Vatten LJ, Nilsen TI, Midthjell K, Wiseth R (2008) Secular decline in mortality from coronary heart disease in adults with diabetes mellitus: cohort study. Br Med J 337:a236

5. Koek HL, Soedamah-Muthu SS, Kardaun JW et al (2007) Shortand long-term mortality after acute myocardial infarction: comparison of patients with and without diabetes mellitus. Eur J Epidemiol 22:883-888

6. Norhammar A, Lindback J, Ryden L, Wallentin L, Stenestrand U (2007) Improved but still high short- and long-term mortality rates after myocardial infarction in patients with diabetes mellitus: a time-trend report from the Swedish Register of Information and Knowledge about Swedish Heart Intensive Care Admission. Heart 93:1577-1583

7. Crowley A, Menon V, Lessard D et al (2003) Sex differences in survival after acute myocardial infarction in patients with diabetes mellitus (Worcester Heart Attack Study). Am Heart J 146:824-831

8. Meisinger C, Heier M, von Scheidt W, Kirchberger I, Hormann A, Kuch B (2010) Gender-specific short and long-term mortality in diabetic vs nondiabetic patients with incident acute myocardial infarction in the reperfusion era (the MONICA/KORA Myocardial Infarction Registry). Am J Cardiol 106:1680-1684

9. Winell KM, Paakkonen R, Pietila A, Niemi MK, Reunanen AR, Salomaa VV (2009) Case fatality rates after first acute coronary syndrome in persons treated for type 2 diabetes show an improving trend. Diabetologia 53:472-480

10. Li YW, Aronow WS (2011) Diabetes mellitus and cardiovascular disease. J Clinic Experiment Cardiol 2:1-9

11. Dudas K, Lappas G, Stewart S, Rosengren A (2011) Trends in outof-hospital deaths due to coronary heart disease in Sweden (1991 to 2006). Circulation 123:46-52
12. Tunstall-Pedoe H, Kuulasmaa K, Amouyel P, Arveiler D, Rajakangas AM, Pajak A (1994) Myocardial infarction and coronary deaths in the World Health Organization MONICA Project. Registration procedures, event rates, and case-fatality rates in 38 populations from 21 countries in four continents. Circulation 90:583-612

13. Lundblad D, Holmgren L, Jansson JH, Naslund U, Eliasson M (2008) Gender differences in trends of acute myocardial infarction events: the Northern Sweden MONICA Study 1985-2004. BMC Cardiovasc Disord 8:17

14. Eriksson M, Holmgren L, Janlert U et al (2011) Large improvements in major cardiovascular risk factors in the population of northern Sweden: the MONICA Study 1986-2009. J Intern Med 269:219-231

15. Isaksson RM, Jansson JH, Lundblad D, Naslund U, Zingmark K, Eliasson M (2011) Better long-term survival in young and middleaged women than in men after a first myocardial infarction between 1985 and 2006. An analysis of 8630 patients in the Northern Sweden MONICA Study. BMC Cardiovasc Disord 11:1

16. Ludvigsson JF, Otterblad-Olausson P, Pettersson BU, Ekbom A (2009) The Swedish personal identity number: possibilities and pitfalls in healthcare and medical research. Eur J Epidemiol 24:659-667

17. Preis SR, Pencina MJ, Hwang SJ et al (2009) Trends in cardiovascular disease risk factors in individuals with and without diabetes mellitus in the Framingham Heart Study. Circulation 120:212-220

18. Eliasson B, Cederholm J, Nilsson P, Gudbjornsdottir S (2005) The gap between guidelines and reality: type 2 diabetes in a National Diabetes Register 1996-2003. Diabet Med 22:1420-1426 